\title{
EIGHTH BRITISH CONGRESS ON THE HISTORY OF MEDICINE
}

The BRITISH SocieTY for the History of Medicine sponsored the Eighth British Congress on the History of Medicine, which met in Liverpool from 8th to 11th September 1971, under the presidency of The Rt. Hon. The Lord Cohen of Birkenhead. The Congress theme was Liverpool's Contributions to Medicine, and a very attractive programme of meetings and activities was enjoyed by all the participants. The scientific sessions were held in the Liverpool Medical Institution, and guests were accommodated in the University of Liverpool.

We have much pleasure in publishing in this number of Medical History (pp. 31086) some of the papers which were read at this Congress. 